\title{
FOOD PHOTOGRAPHY PADA IKLAN DI INSTAGRAM
}

\author{
Bobby Halim ${ }^{1)}$, Yosef Yulius ${ }^{2)}$ \\ 1), 2), Program Studi Desain Komunikasi Visual Universitas Indo Global Mandiri Jl. Jend. Sudirman No. 629 KM.4 \\ Palembang Kode Pos 30129 \\ e-mail: bobby_dkv@uigm.ac.id ${ }^{l)}$,yosef_dkv@uigm.ac.id ${ }^{2)}$,
}

\begin{abstract}
In an advertisement, sometimes there is a meaning that is not straightforwardly presented. Every product advertisement that uses the product is inseparable from the camera point of view. FOOD PHOTOGRAPHY ON ADVERTISING IN INSTAGRAM examines the relationship between camera placement (angle) in influencing the message conveyed by a product advertisement and how photography is used as visual rhetoric. The study was conducted qualitatively with a film semiotic analysis approach. Data on FOOD PHOTOGRAPHY ON ADVERTISING IN INSTAGRAM is grouped with only 1 structure, namely Visual Structure. It was analyzed diachronic using the signifier and signified views.

The purpose of this research is to find out and describe the meanings contained in food product advertisements on social media, where Instagram is the media chosen as the sample.

This study uses several points of view in its study, namely a close point of view (Close Up), a Medium Viewpoint (Medium Close Up), and a flat point of view (flat lay).
\end{abstract}

Keywords: advertising, semiotics, photos, social media

\begin{abstract}
ABSTRAK
Dalam sebuah iklan terkadang terdapat makna yang disajikan tidak lugas. Setiap iklan produk yang menggunakan produk, tidak terlepas dari sudut pandang kamera. FOOD PHOTOGRAPHY PADA IKLAN DI INSTAGRAM menelaah hubungan peletakan kamera (angle) dalam mempengaruhi pesan yang disampaikan oleh sebuah iklan produk dan bagaimana fotografi digunakan sebagai retorika visual. Kajian dilakukan secara kualitatif dengan pendekatan analisis semiotika film. Data FOOD PHOTOGRAPHY PADA IKLAN DI INSTAGRAM dikelompokan hanya 1 struktur, yaitu Struktur Visual. Dianalisis secara diakronik dengan menggunakan pandangan signifier (penanda) dan signified (petanda). Tujuan penelitian ini adalah untuk mengetahui dan mendeskripsikan makna-makna yang terdapat pada iklan-iklan produk makanan di media sosial,dimana Instagram menjadi media yang dipilih sebagai sample-nya.

Penelitian ini menggunakan beberapa sudut pandang dalam pengkajiannya,yaitu sudut pandang dekat (Close Up), sudut pandang Sedang (Medium Close Up), dan sudut pandang Datar (flat lay)
\end{abstract}

Kata Kunci : iklan, semiotika, foto, media sosial

\section{Pendahuluan}

Kuliner sudah menjadi hal yang lazim saat ini,bahkan menjadi tren bagi setiap kalangan baik muda maupun tua. Makan tidak hanya menjadi kebutuhan dasar tetapi ada pergeseran kebutuhan menjadi kebutuhan tersier, dimana makan sebagai kebutuhan primer sudah terpenuhi maka orang mencari makan sebagai kebutuhan tersier sebagai kebutuhan pelengkap. Kebutuhan pelengkap disini maksudnya yaitu bisa sebatas makan jajanan, makanan ringan yang tidak melulu makanan berat.

Hampir di setiap perkotaan,khususnya kota-kota besar Indonesia tersebar tempat-tempat makan,restoran,warung,pujasera bahkan kios yang menjajakan berbagai jenis kuliner baik jajanan maupun makanan berat. Makanan menjadi sebuah sarana hiburan karena dengan makan enak seseorang dapat merasa senang dan gembira. Hanya bermodalkan beberapa lembar uang, kesenangan dapat diraih dengan mudah dan murah.

Untuk sebuah minuman kekinian seperti Thai Tea dapat diperoleh dengan uang belasan ribu saja, tentu dengan kualitas yang biasa. Berbeda dengan yang harga puluhan ribu, rasa lebih kuat dan ada juga yang terdapat topping di dalamnya. Begitu juga jajanan makanan, ada yang dapat diperoleh hanya beberapa ribu saja. Para pedagang umumnya mengejar kuantitas agar tembus omzet. Dengan harga murah para pedagang berharap banyak konsumen yang membeli produknya. Tidak hanya pedagang kecil, para pengusaha kelas menengah ke atas pun berlomba-lomba untuk mengejar omzet tinggi dengan mempromosikan produk-produknya.

Dengan kemajuan teknologi, promosi saat ini menjadi banyak pilihan, dari yang berbiaya tinggi hingga berbiaya rendah bahkan gratis. Salah satu media promosi dengan biaya rendah yaitu platform Instagram. Instagram milik perusahaan Facebook, sebelum diakuisisi oleh 
Facebook, platform ini dibuat oleh Kevin Systrom and Mike Krieger, berwargakenegaraan Amerika Serikat.

Instagram (juga disebut IG atau Insta) adalah sebuah aplikasi berbagi foto dan video yang memungkinkan pengguna mengambil foto, mengambil video, menerapkan filter digital, dan membagikannya ke berbagai layanan jejaring sosial, termasuk milik Instagram sendiri.[10] Satu fitur yang unik di Instagram adalah memotong foto menjadi bentuk persegi, sehingga terlihat seperti hasil kamera Kodak Instamatic dan polaroid. Hal ini berbeda dengan rasio aspek 4:3 atau 16:9 yang umum digunakan oleh kamera pada peranti bergerak.

Instagram dapat digunakan di iPhone, iPad atau iPod Touch versi apapun dengan sistem operasi iOS 7.0 atau yang terbaru, telepon genggam Android apapun dengan sistem operasi versi 2.2 (Froyo) ke atas, dan Windows Phone 8. Aplikasi ini dapat diunduh melalui Apple App Store dan Google Play.

\section{Rumusan Masalah}

Bagaimana mengetahui ciri-ciri visual fotografi iklan di media sosial yang paling tepat?

\section{Tujuan}

oMengetahui pengaturan kamera yang terbaik dalam menghasilkan foto iklan yang disukai kalangan banyak

oMengetahui dampak teknik fotografi pada iklan di media sosial

\section{Pendekatan dan Metode}

Penulis menggunakan pendekatan semiotika dalam mengkaji rumusan masalah.

Semiotika adalah suatu bentuk strukturalisme, karena ia berpandangan bahwa manusia tidak bisa mengetahui dunia melalui istilah-istilahnya sendiri, melainkan hanya melalui struktur-struktur konseptual dan linguistik dalam kebudayaan. Bagi para strukturalis, tugas ilmuwan adalah menyingkap struktur konseptual yang berdasarkan struktur tersebut berbagai kebudayaan mengorganisasikan persepsi dan pemahamannya atas dunia. Upaya strukturalisme adalah menemukan cara manusia memahami dunia, bukan seperti apakah dunia itu.

Penggunaan semiotika sebagai metode pembacaan di dalam berbagai cabang keilmuan dimungkinkan, oleh karena adanya kecenderungan dewasa ini untuk memandang berbagai diskursus (di sini khususnya sosial) sebagai fenomena bahasa. Dan didalam metode semiotika ini ada berbagai elemen dasar, yaitu tanda (penanda/petanda), aksis tanda (sitagma/sistem) tingkatan tanda (denotasi/konotasi), serta relasi tanda (metafora/metomini).

Semiotika (semiotics) didefinisikan oleh Ferdinand de Saussure di dalam course in general linguistics, "sebagai ilmu yang mengkaji tentang tanda sebagai bagian dari kehidupan." Implisit dalam definisi Saussure adalah prinsip, bahwa semiotika sangat menyandarkan dirinya pada aturan main (rule) atau kode sosial (social code) yang berlaku di dalam masyarakat, sehingga tanda dapat dipahami maknanya secara kolektif. Saussure juga menjelaskan perbedaan antara dua model analisis dalam penelitia bahasa, yaitu analisis diakronik (diachronic) dan analisis sinkronik (synchronic). Analisis diakronik adalah analisis tentang perubahan historis bahasa, yaitu yaitu bahasa dalam dimensi waktu, perkembangan dan perubahannya. Analisis sinkronik, adalah analisis yang didalamnya kita mengambil irisan sejarah dan mengakaji struktur bahasa hanya pada satu moment waktu tertentu saja, bukan dalam konteks perubahan historisnya. Apa yang disebut dengan pendekatan strukturalisme (structuralism) dalam bahasa, adalah pendekatan yang melihat hanya struktur bahasa, dan mengabaikan konteks waktu, perubahan, sejarahnya. Semiotika, sebagaimana dijelaskan oleh Fedinand de saussure adalah "ilmu yang mempelajari peran tanda (sign) sebagai bagian dari kehidupan sosial". Semiotika adalah ilmu yang mempelajari struktur, jenis, tipologi, serta relasi-relasi tanda dalam penggunaannya di dalam masyarakat. Oleh sebab itu, semiotika mempelajari relasi diantara komponen-komponen tersebut dengan masyarakat penggunanya.

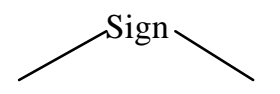

Signifier dan Signified

Gambar 1.1 Sistem tanda menurut Saussure

Semiotika merupakan sebuah cabang keilmuan yang memperlihatkan pengaruh semakin penting sejak empat dekade yang, tidak saja sebagai metode kajian (decoding), akan tetapi sebagai metode penciptaan (encoding). Semiotika telah berkembang menjadi sebuah model atau paradigm bagi berbagai keilmuan yang sangat luas yang menciptakan cabang-cabang semiotika khusus.

Iklan sebagai sebuah teks adalah sistem tanda terorganisir menurut kode - kode yang merefleksikan nilai - nilai tertentu, sikap dan juga keyakinan tertentu. Setiap pesan dalam iklan dua tingkatan makna yang dinyatakan secara eksplisit di permukaan dan makna yang dkemukakan secara implisit di balik permukaan iklan. Dengan demikian, semiotika menjadi metode yang sesuai untuk mengetahui kontruksi makna yang terjadi dalam iklan dengan menekankan peran sistem tanda dengan konstruksi realitas, maka melaui semiotika ideologi - ideologi di balik iklan bisa dibongkar.

Di dalam bidang desain khususnya, semiotika digunakan sebagai sebuah paradigma. Baik dalam pembacaan (reading) maupun penciptaan (creating) disebabkan adanya kecenderungan akhir-akhir ini dalam wacana desain untuk melihat objek-objek desain sebagai sebuah fenimena bahasa, yang di dalamnya terdapat tanda (sign), pesan yang ingin disampaikan (message) aturan atau kode yang mengatur (code), serta orangorang yang terlibat di dalamnya sebagai subjek bahasa (audiens, reader, user)

\section{TEORI DESAIN KOMUNIKASI VISUAL}

Pada umumnya media-media desain komunikasi visual dipakai dalam upaya promosi kesehatan/ kampanye 
kesehatan, adapun media-media tersebut antara lain seperti poster, flyer, leaflet, foto, ilustrasi, dan video. Setiap media diharapkan memiliki unsur- unsur dan nilai-nilai yang terkandung dalam bidang keilmuan desain komunikasi visual, sehingga pesan yang ingin disampaikan menjadi tidak tepat sasaran. (Yulius, 2016:43).

Sebagaimana diungkapkan Kusrianto (2007:2) Desain Komunikasi visual didefinisikan sebagai berikut :

"Desain komunikasi visual adalah suatu disiplin ilmu yang bertujuan mempelajari konsep-konsep komunikasi serta ungkapan kreatif melalui berbagai media untuk menyampaikan pesan dan gagasan secara visual dengan mengelola elemen- elemen grafis yang berupa bentuk dan gambar, tatanan huruf, serta komposisi warna dan layout (tata letak/perwajahan). Dengan demikian gagasan bisa diterima oleh orang atau kelompok yang menjadi sasaran penerima pesan".

Dalam pembuatan sebuah media desain, proposi merupakan salah satu aspek yang membantu target sasaran dari perancangan kita mengenal bentuk-bentuk visual. Pada umumnya proporsi berkenaan dengan hubungan ukuran bagian-bagian suatu bentuk sepeti lebar dan tinggi. Komposisi lebar dan tinggi biasnya dibandingkan/dibuat ukuran perbandingan sebagai bahan untuk menentukan proporsi dalam bentuk dua dimensi sehingga terbentuk suatu harmoni. (Safanayong, 2006:38)

Selain menciptakan harmoni, proporsi dapat membantu kita lebih mengerti tempat kita dalam alam semesta terutama dalam merasakan kesan ekspresi keteraturan yang tinggi. Proporsi sendiri dapat membuat suatu bentuk visual menjadi lebih menarik dan dapat meningkatkan fungsi komunikasi dari karya yang dibuat.

\section{TEORI VISUAL LAYOUT}

Layout merupakan tataletak elemen-elemen desain terhadap suatu media untuk mendukung konsep/pesan, yang pada perkembangannya proses layouting / melayout sering kali dikatakan sebagai mendesain (Rustan, 2009:1). Menurut Lia dan Kirana, proses layout merupakan salah satu hal utama dalam suatu desain komunikasi visual, sebuah desain harus memiliki layout yang terpadu (2016:74).

\section{Pembahasan}

Penulis mengambil sample 2 akun Instagram yang khusus membahas kuliner di Palembang, yaitu akun @makanapa dan @makanlemakplg. 2 akun tersebut penulis pilih karena kepopulerannya dan kredibilitasnya. Kepopulerannya dapat diukur dari jumlah followernya, sedangkan kredibilitasnya dapat dinilai dari tenant-tenant yang di-review oleh tim mereka.

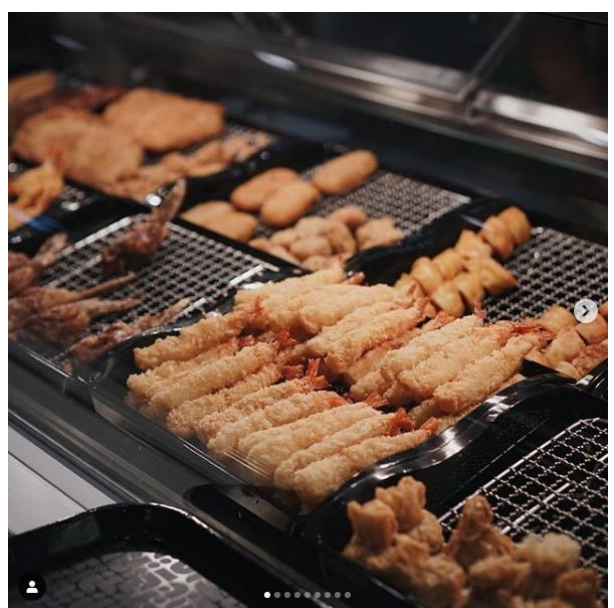

Gambar 1

Promosi produk@hokben id

\begin{tabular}{|l|l|}
\hline \multicolumn{1}{|c|}{ Signifier } & \multicolumn{1}{c|}{ Signified } \\
\hline $\begin{array}{l}\text { Menu Gorengan Hoka } \\
\text { Hoka Bento }\end{array}$ & $\begin{array}{l}\text { iklan ditampilkan dengan } \\
\text { shot MCU dan bukaan } \\
\text { besar sehingga tercipta } \\
\text { depth of field }\end{array}$ \\
\hline
\end{tabular}

\begin{tabular}{|c|c|}
\hline Shot & Visual \\
\hline MCU & Menu Gorengan Hoka Hoka Bento \\
\hline
\end{tabular}

Pada level signifier (penanda) memvisualisasikan Menu Gorengan Hoka Hoka Bento.

Pada level signified (petanda) yaitu iklan ditampilkan dengan shot MCU dan bukaan besar sehingga tercipta depth of field.

Signification atau makna yang ingin disampaikan yaitu dengan posisi kamera yang tidak terlalu dekat, komposisi produk (makanan) yang disusun secara aktual,maka calon konsumen dapat membayangkan kenikmatan produk sehingga tertarik untuk membeli.

Teknik pengambilan gambar pada foto ini adalah Medium Close Up, melalui teknik MCU, jelas makanan ditampilkan menarik.

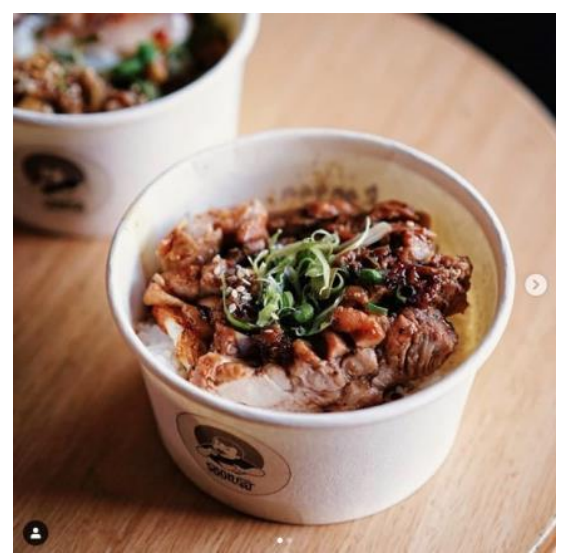

Gambar 2

Promosi produk@makanmangkok.soonfat 


\begin{tabular}{|c|l|}
\hline \multicolumn{1}{|c|}{ Signifier } & \multicolumn{1}{c|}{ Signified } \\
\hline 1 porsi menu Soon Fat. & $\begin{array}{l}\text { iklan ditampilkan dengan shot } \\
\text { MCU dan bukaan besar } \\
\text { sehingga tercipta depth of } \\
\text { field. }\end{array}$ \\
\hline
\end{tabular}

\begin{tabular}{|l|c|}
\hline Shot & Visual \\
\hline MCU & 1 porsi menu Soon Fat. \\
\hline
\end{tabular}

Pada level signifier (penanda) memvisualisasikan 1 porsi menu Soon Fat.

Pada level signified (petanda) yaitu iklan ditampilkan dengan shot MCU dan bukaan besar sehingga tercipta depth of field.

Signification atau makna yang ingin disampaikan yaitu dengan posisi kamera yang tidak terlalu dekat dan miring dari atas, komposisi produk (makanan) yang disusun tidak penuh,hanya ada 1 mangkuk lain di belakang, maka calon konsumen dapat membayangkan kenikmatan produk sehingga tertarik untuk membeli..

Teknik pengambilan gambar pada foto ini adalah Medium close up, melalui teknik MCU,

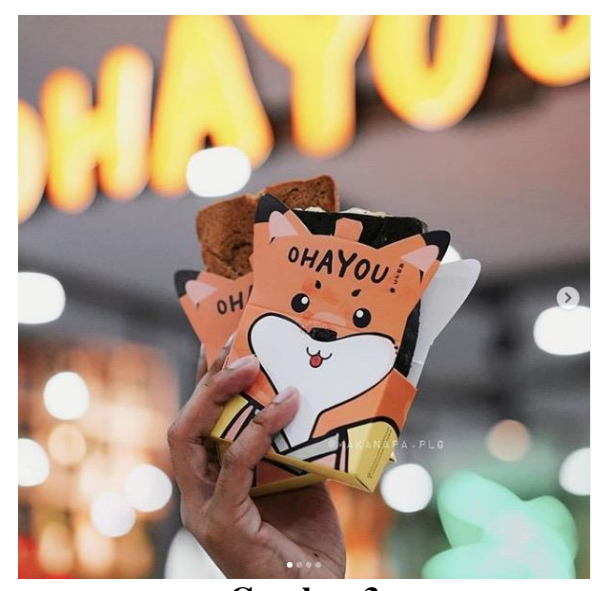

Gambar 3

Promosi produk@ ohayou

\begin{tabular}{|l|l|}
\hline \multicolumn{1}{|c|}{ Signifier } & \multicolumn{1}{c|}{ Signified } \\
\hline $\begin{array}{l}\text { Roti Ohayou beserta } \\
\text { packaging-nya }\end{array}$ & $\begin{array}{l}\text { iklan ditampilkan dengan shot } \\
\text { MCU dan bukaan besar } \\
\text { sehingga tercipta depth of } \\
\text { field, iklan fokus ke produk } \\
\text { dimana packagingnya sangat } \\
\text { menarik }\end{array}$ \\
\hline
\end{tabular}

\begin{tabular}{|c|c|}
\hline Shot & Visual \\
\hline MCU & Roti Ohayou beserta packaging-nya \\
\hline
\end{tabular}

Pada level signifier (penanda) memvisualisasikan Roti Ohayou beserta packaging-nya.

Pada level signified (petanda) yaitu iklan ditampilkan dengan shot MCU dan bukaan besar sehingga tercipta depth of field, iklan fokus ke produk dimana packagingnya sangat menarik.

Signification atau makna yang ingin disampaikan yaitu dengan packaging yang unik dan menarik, settingan kamera yang tepat,maka iklan Roti Ohayou ini sangat memukau.

Teknik pengambilan gambar pada foto ini adalah MCU, dengan bukaan besar maka Point Of Interest sangat kuat.

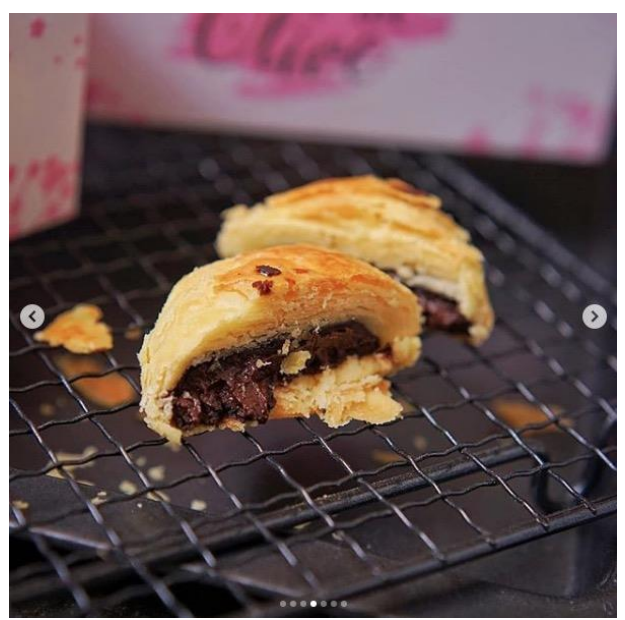

Gambar 4

Promosi produk @ olivetwinie

\begin{tabular}{|l|l|}
\hline \multicolumn{1}{|c|}{ Signifier } & \multicolumn{1}{c|}{ Signified } \\
\hline $\begin{array}{l}\text { Tampilan dalam Kue } \\
\text { Olivetwinie }\end{array}$ & $\begin{array}{l}\text { iklan ditampilkan dengan } \\
\text { shot CU dan bukaan besar } \\
\text { sehingga tercipta depth of } \\
\text { field, isi dari Kue } \\
\text { Olivetwinie terlihat jelas }\end{array}$ \\
\hline
\end{tabular}

\begin{tabular}{|c|c|}
\hline Shot & Visual \\
\hline CU & Tampilan dalam Kue Olivetwinie \\
\hline
\end{tabular}

Pada level signifier (penanda) memvisualisasikan tampilan dalam Kue Olivetwinie.

Pada level signified (petanda) yaitu iklan ditampilkan dengan shot $\mathrm{CU}$ dan bukaan besar sehingga tercipta depth of field, isi dari Kue Olivetwinie terlihat jelas.

Signification atau makna yang ingin disampaikan yaitu dengan posisi kamera atau lensa yang dekat dengan produk, detil produk (makanan) kue tampil sangat meyakinkan, isi dari Kue Olivetwinie yang begitu menggoda.

Teknik pengambilan gambar pada foto ini adalah close up, mempertegas kelebihan dari produk Olivetwinie. 


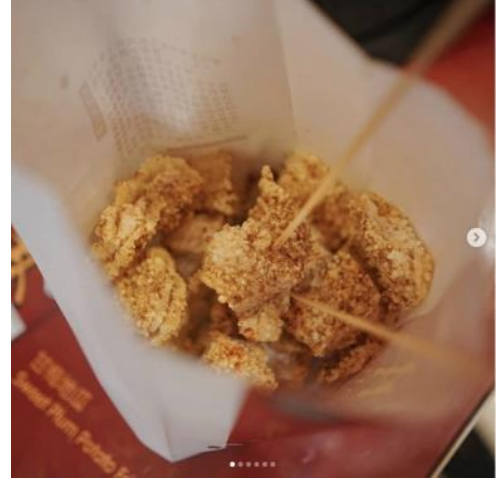

Gambar 5

Promosi produk@shihlin transmart

\begin{tabular}{|l|l|}
\hline \multicolumn{1}{|c|}{ Signifier } & \multicolumn{1}{c|}{ Signified } \\
\hline $\begin{array}{l}\text { Shihlin di dalam } \\
\text { kemasannya }\end{array}$ & $\begin{array}{l}\text { iklan ditampilkan dengan } \\
\text { shot Flat Lay dan bukaan } \\
\text { besar sehingga tercipta } \\
\text { depth of field, isi dari } \\
\text { kemasan Shihlin begitu } \\
\text { menggoda untuk dinikmati }\end{array}$ \\
\hline
\end{tabular}

\begin{tabular}{|l|c|}
\hline Shot & Visual \\
\hline Flat Lay & Shihlin di dalam kemasannya \\
\hline
\end{tabular}

Pada level signifier (penanda) memvisualisasikan Shihlin di dalam kemasannya.

Pada level signified (petanda) yaitu iklan ditampilkan dengan shot Flat Lay dan bukaan besar sehingga tercipta depth of field, isi dari kemasan Shihlin begitu menggoda untuk dinikmati.

Signification atau makna yang ingin disampaikan yaitu dengan posisi kamera atau lensa yang tidak terlalu dekat dengan produk,posisi dari atas, maka sangat menggoda calon konsumen untuk membeli dan menikmati produk Shihlin tersebut.

Teknik pengambilan gambar pada foto ini adalah Flat Lay, agar calon konsumen dapat merasakan seolah-olah ingin mengambil dan menikmati daging Shihlin.

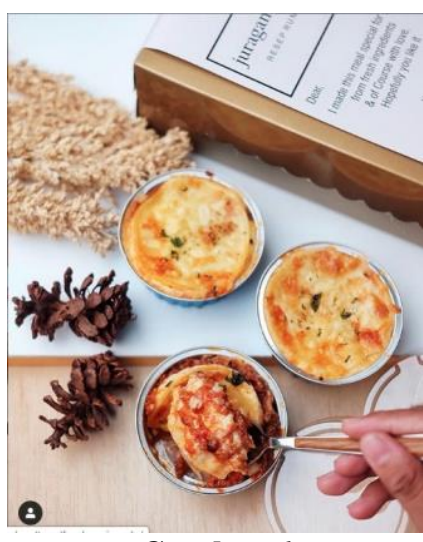

Gambar 6

Promosi produk@juragan_loyang

\begin{tabular}{|l|l|}
\hline \multicolumn{1}{|c|}{ Signifier } & \multicolumn{1}{c|}{ Signified } \\
\hline $\begin{array}{l}\text { Produk Juragan Loyang } \\
\text { tampak atas }\end{array}$ & $\begin{array}{l}\text { iklan ditampilkan dengan shot } \\
\text { Flat Lay, komposisi foto } \\
\text { diatur sedemikian rupa dengan } \\
\text { metode Rule Of Third. }\end{array}$ \\
\hline
\end{tabular}

\begin{tabular}{|c|c|}
\hline Shot & Visual \\
\hline Flat Lay & Produk Juragan Loyang tampak atas \\
\hline
\end{tabular}

Pada level signifier (penanda) memvisualisasikan Produk Juragan Loyang tampak atas.

Pada level signified (petanda) yaitu iklan ditampilkan dengan shot Flat Lay, komposisi foto diatur sedemikian rupa dengan metode Rule Of Third.

Signification atau makna yang ingin disampaikan yaitu dengan penambahan elemen-elemen pada foto yang tidak hanya menampilkan produk, iklan Juragan Loyang berusaha menampilkan sisi estetis dan makna bahan yang terkandung dari produknya,yaitu gandum yang ditampilkan pada sisi kiri atas.

Teknik pengambilan gambar pada foto ini adalah Flat Lay, agar visualisasi terlihat menarik.

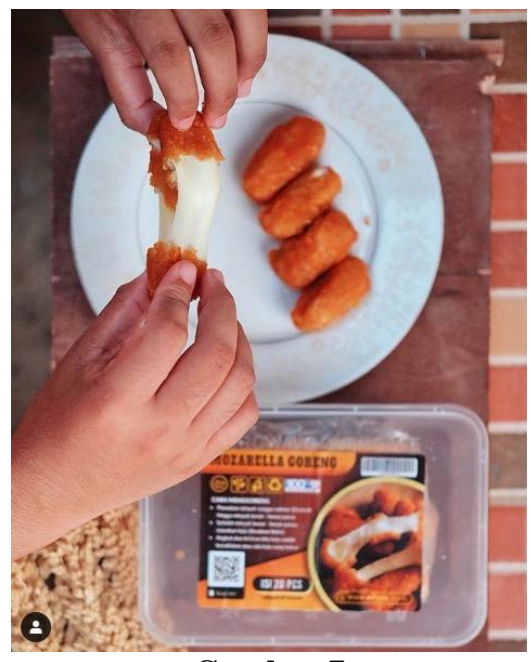

Gambar 7

Promosi produk @oifyoo_palembang

\begin{tabular}{|l|l|}
\hline \multicolumn{1}{|c|}{ Signifier } & \multicolumn{1}{c|}{ Signified } \\
\hline $\begin{array}{l}\text { Mozarella Goreng dari } \\
\text { Oifyoo }\end{array}$ & $\begin{array}{l}\text { iklan ditampilkan dengan } \\
\text { shot Flat Lay, visual tangan } \\
\text { membuka-membelah 1 } \\
\text { buah Mozarella Goreng } \\
\text { sehingga isinya terlihat }\end{array}$ \\
\hline
\end{tabular}

\begin{tabular}{|c|c|}
\hline Shot & Visual \\
\hline Flat Lay & Mozarella Goreng dari Oifyoo \\
\hline
\end{tabular}


Pada level signifier (penanda) memvisualisasikan Mozarella Goreng dari Oifyoo.

Pada level signified (petanda) yaitu iklan ditampilkan dengan shot Flat Lay, visual tangan membuka-membelah 1 buah Mozarella Goreng sehingga isinya terlihat. Signification atau makna yang ingin disampaikan yaitu agar calon konsumen dapat melihat kualitas dari isi Mozarella Goreng.

Teknik pengambilan gambar pada foto ini adalah Flat Lay dan bukaan besar, sehingga Point Of Interest tertuju kepada Mozarella Goreng yang sedang dibelah.

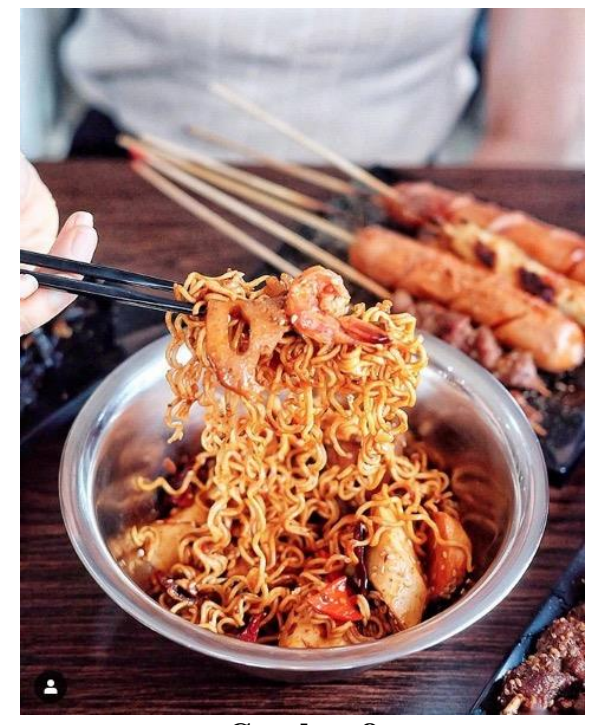

Gambar 8

Promosi produk@shaokaopalembang

\begin{tabular}{|c|l|}
\hline \multicolumn{1}{|c|}{ Signifier } & \multicolumn{1}{c|}{ Signified } \\
\hline Mie khas Shaokao & $\begin{array}{l}\text { iklan ditampilkan dengan } \\
\text { shot MCU, visual tangan } \\
\text { sedang menyumpit mie } \\
\text { beserta toppingnya yang } \\
\text { melimpah }\end{array}$ \\
\hline
\end{tabular}

\begin{tabular}{|c|c|}
\hline Shot & Visual \\
\hline MCU & Mie khas Shaokao \\
\hline
\end{tabular}

Pada level signifier (penanda) memvisualisasikan Mie khas Shaokao.

Pada level signified (petanda) yaitu iklan ditampilkan dengan shot MCU, visual tangan sedang menyumpit mie beserta toppingnya yang melimpah.

Signification atau makna yang ingin disampaikan yaitu Mie khas Shaokao begitu menarik dan menggoda dengan topping yang melimpah.

Teknik pengambilan gambar pada foto ini adalah MCU dan bukaan besar, karena Shaokao ingin mie tersebut menjadi point of interest dan menggugah selera.

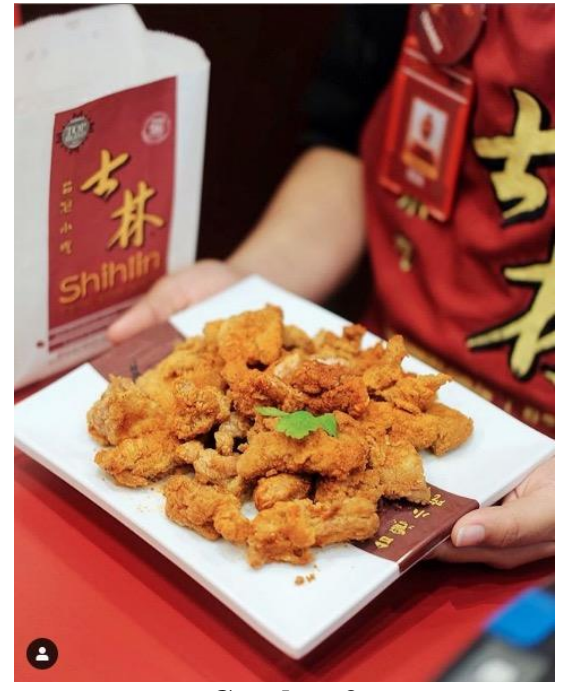

Gambar 9

Promosi produk@shihlinsnacksid

\begin{tabular}{|l|l|}
\hline \multicolumn{1}{|c|}{ Signifier } & \multicolumn{1}{c|}{ Signified } \\
\hline Visual daging Shihlin & $\begin{array}{l}\text { iklan ditampilkan dengan } \\
\text { shot MCU, visual daging } \\
\text { Shihlin disajikan diatas } \\
\text { sebuah piring khusus dari } \\
\text { Shihlin }\end{array}$ \\
\hline
\end{tabular}

\begin{tabular}{|c|c|}
\hline Shot & Visual \\
\hline MCU & $\begin{array}{c}\text { Visual daging Shihlin di atas sebuah } \\
\text { piring }\end{array}$ \\
\hline
\end{tabular}

Pada level signifier (penanda) memvisualisasikan daging Shihlin.

Pada level signified (petanda) yaitu iklan ditampilkan dengan shot MCU, visual daging Shihlin disajikan diatas sebuah piring khusus dari Shihlin.

Signification atau makna yang ingin disampaikan yaitu Shihlin dapat disajikan sebagai menu utama / lauk di rumah.

Teknik pengambilan gambar pada foto ini adalah MCU, sehingga terlihat jelas properti yang dipakai sebagai penguat makna.

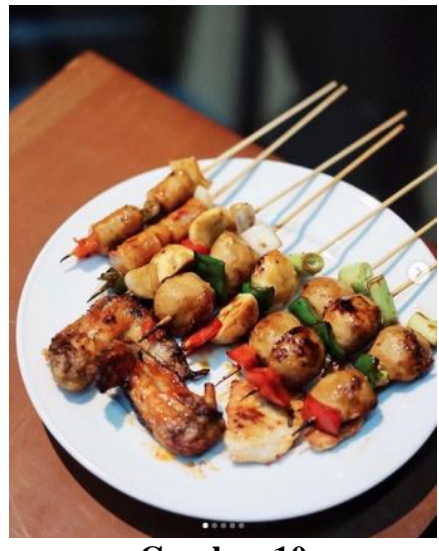

Gambar 10

Promosi produk @fresqa resto Batiqa Hotel Palembang 


\begin{tabular}{|l|l|}
\hline \multicolumn{1}{|c|}{ Signifier } & \multicolumn{1}{c|}{ Signified } \\
\hline $\begin{array}{l}\text { Tampilan sate BBQ } \\
\text { di Fresqa Resto } \\
\text { Batiqa Hotel }\end{array}$ & $\begin{array}{l}\text { iklan ditampilkan dengan shot } \\
\text { MCU, visual sate BBQ disajikan } \\
\text { diatas sebuah piring dari Fresqa } \\
\text { Resto }\end{array}$ \\
\hline
\end{tabular}

\begin{tabular}{|c|c|}
\hline Shot & Visual \\
\hline MCU & $\begin{array}{c}\text { Tampilan sate BBQ di Fresqa Resto } \\
\text { Batiqa Hotel }\end{array}$ \\
\hline
\end{tabular}

Pada level signifier (penanda) memvisualisasikan sate BBQ di Fresqa Resto Batiqa Hotel.

Pada level signified (petanda) yaitu iklan ditampilkan dengan shot MCU, visual sate BBQ disajikan diatas sebuah piring dari Fresqa Resto.

Signification atau makna yang ingin disampaikan yaitu Fresqa Resto menyajikan sate BBQ yang begitu menggugah selera.

Teknik pengambilan gambar pada foto ini adalah MCU, karena Fresqa Resto ingin menampilkan penyajian sate BBQ yang sederhana tapi menggugah selera.

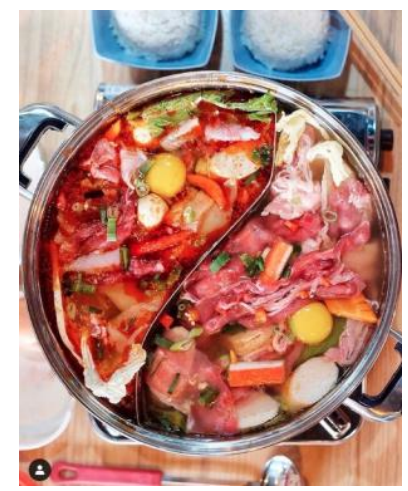

Gambar 11

Promosi produk @baropi.id

\begin{tabular}{|l|l|}
\hline \multicolumn{1}{|c|}{ Signifier } & \multicolumn{1}{c|}{ Signified } \\
\hline $\begin{array}{l}\text { Tampilan Suki dari } \\
\text { Baropi }\end{array}$ & $\begin{array}{l}\text { iklan ditampilkan dengan shot } \\
\text { Flat Lay, visual Suki disajikan } \\
\text { di dalam panic yang sedah } \\
\text { mendidih }\end{array}$ \\
\hline
\end{tabular}

\begin{tabular}{|c|c|}
\hline Shot & Visual \\
\hline Flat Lay & Tampilan Suki dari Baropi \\
\hline
\end{tabular}

Pada level signifier (penanda) memvisualisasikan Suki dari Baropi.

Pada level signified (petanda) yaitu iklan ditampilkan dengan shot Flat Lay, visual Suki disajikan di dalam panic yang sedah mendidih.

Signification atau makna yang ingin disampaikan yaitu Suki di Baropi begitu banyak pilihan dan melimpah.
Teknik pengambilan gambar pada foto ini adalah Flat Lay, karena Baropi ingin menampilkan Suki-nya yang melimpah dan menggugah selera.

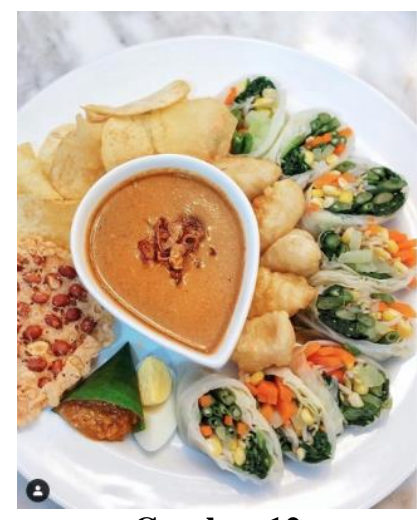

Gambar 12

Promosi produk@equatore_rooftop

\begin{tabular}{|l|l|}
\hline \multicolumn{1}{|c|}{ Signifier } & \multicolumn{1}{c|}{ Signified } \\
\hline $\begin{array}{l}\text { Tampilan Gado-gado } \\
\text { khas Equatore }\end{array}$ & $\begin{array}{l}\text { iklan ditampilkan dengan shot } \\
\text { Rooftop }\end{array}$ \\
& $\begin{array}{l}\text { Flat Lay, sehingga calon } \\
\text { konsumen dapat } \\
\text { membayangkan kelezatan } \\
\text { Gado-gado khas Equatore } \\
\text { Rooftop }\end{array}$ \\
& \\
\hline
\end{tabular}

\begin{tabular}{|c|c|}
\hline Shot & Visual \\
\hline Flat Lay & Gado-gado khas Equatore Rooftop \\
\hline
\end{tabular}

Pada level signifier (penanda) memvisualisasikan Gadogado khas Equatore Rooftop.

Pada level signified (petanda) yaitu iklan ditampilkan dengan shot Flat Lay, sehingga calon konsumen dapat membayangkan kelezatan Gado-gado khas Equatore Rooftop.

Signification atau makna yang ingin disampaikan yaitu Equatore Rooftop ingin meyakinkan calon konsumen bahwa gado-gado-nya begitu special dan nikmat,tidak hanya sekedar cantik.

Teknik pengambilan gambar pada foto ini adalah Flat Lay, karena Equatore Rooftop ingin menampilkan gadogado-nya secara keseluruhan.

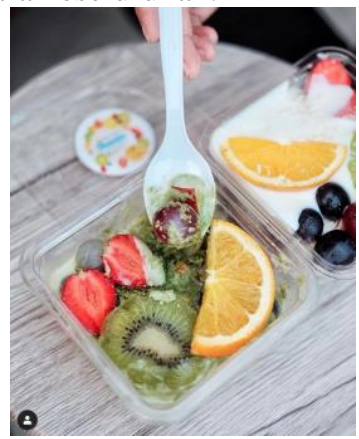

Gambar 13

Promosi produk@sparklingsaladshavier 


\begin{tabular}{|c|l|}
\hline Signifier & \multicolumn{1}{|c|}{ Signified } \\
\hline $\begin{array}{c}\text { Tampilan salad buah dari } \\
\text { Sparkling Salad Shavier }\end{array}$ & $\begin{array}{l}\text { tangan kepiting ke tangan } \\
\text { pegang garpu sebagai } \\
\text { keberagaman }\end{array}$ \\
\hline
\end{tabular}

\begin{tabular}{|l|c|}
\hline Shot & Visual \\
\hline MCU & salad buah dari Sparkling Salad Shavier \\
\hline
\end{tabular}

Pada level signifier (penanda) memvisualisasikan salad buah dari Sparkling Salad Shavier.

Pada level signified (petanda) yaitu iklan ditampilkan dengan shot MCU, sehingga calon konsumen dapat membayangkan kesegaran salad buah dari Sparkling Salad Shavier.

Signification atau makna yang ingin disampaikan yaitu Sparkling Salad Shavier berusaha menggugah selera calon konsumen melalui iklan tersebut.

Teknik pengambilan gambar pada foto ini adalah MCU, karena Sparkling Salad Shavier ingin menampilkan isi dan kemasan salad buahnya yang praktis dan higienis.

\section{Fotografi Sebagai Gaya Hidup Saat Ini}

Kemajuan teknologi Fotografi,memudahkan orang dalam kehidupan sehari-hari,baik di tingkat kota maupun desa. Masyarakat kota yang menginginkan kecepatan dalam menghasilkan sesuatu,sehingga industri terpacu untuk menghasilkan produk dan jasa yang memudahkan kehidupan manusia. Hampir setiap orang memiliki handphone, tua-muda,kaya-miskin hampir memiliki handphone untuk menemani kehidupan seharihari. Dan teknologi kamera sudah disematkan di hampir setiap handphone.

Smartphone yang tentunya sudah memiliki kamera, menjadi alat fotografi yang mudah dan baik. Semakin hari,teknologi kamera pada Smartphone semakin baik. Hampir setara kualitasnya dengan kamera profesional. Bahkan banyak fotografer profesional menggunakan Smartphone untuk pekerjaanpekerjaannya.

\section{Instagram Menjadi Sarana Promosi Efektif Bagi Pengusaha Kecil}

Persentase Wiraswasta atau Pengusaha di Indonesia terbilang kecil,tidak sampai $10 \%$ setiap tahunnya. Banyak faktor yang menyebabkan hal ini terjadi,salah satunya yaitu tingginya biaya promosi dalam mengiklankan produk maupun jasanya.

Dengan kemajuan teknologi komputer dan fotografi, banyak orang khususnya pengusaha kecil diuntungkan. Instagram sebagai salah satu media sosial populer di Indonesia, dapat berfungsi sebagai media iklan (promosi) dengan harga murah bahkan gratis. Selain akun biasa, Instagram pun menyediakan akun bisnis agar para pengusaha dapat mengatur promosinya menjadi lebih baik dan fokus. Fitur-fitur pada akun bisnis lebih banyak dan lengkap dibanding akun biasa.

\section{Food Photography Menjadi Bagian Dari Keseharian Masyarakat Urban}

Food Photography menjadi hal yang lumrah bagi pengguna media sosial, khususnya di Instagram. Food Photography banyak diterapkan oleh Food Blogger. Food Photography selain menjadi bagian hobi,dapat pula diterapkan untuk komersil. Banyak perusahaan baik kecil maupun besar,khususnya di bidang makanan,menggunakan teknik Food Photography dalam mempromosikan produk-produknya.

Dengan kemajuan teknologi kamera dan handphone membuat Food Photography menjadi hal yang tidak sulit. Apalagi ilmu-ilmu semakin mudah didapatkan saat ini melalui internet, Food Photography dapat diterapkan dimanapun bahkan di dalam rumah pribadi.

\section{Kesimpulan Dan Saran}

\section{Kesimpulan}

Food Photography sebagai alat iklan di Instagram, terbilang efektif karena sebagian besar tepat sasaran yaitu kaum muda yang sering mengakses Instagram dan juga biaya akun bisnis yang terjangkau.

Food Photography mungkin masih dapat berkembang lagi ke depannya khususnya di media sosial. Dalam penelitian ini khusus mengangkat sisi positif dari Food Photography, agar peneliti fokus.

\section{Saran}

\section{Saran Akademis}

1. Diharapkan penelitian sejenis dapat menggunakan metode-metode lain dari semiotika. Penelitian ini memakai metode dari Ferdinand de Saussure yaitu Signifier dan Signified. Terdapat metode lain yang kiranya dapat digunakan dalam meneliti sebuah iklan televisi dari tokoh - tokoh semiotika lain, seperti Charles Sanders Peirce, Roman Jakobson, Louis Hjelmslev, Roland Barthes hingga Jacques Derrida.

2. Penelitian ini ingin mendorong penelitianpenelitian lain untuk mengkaji iklan-iklan di media sosial yang menerapkan teknik fotografi dalam proses kreatifnya, dalam mencari makna-makna eksplisit maupun implisit yang terkandung.

\section{Saran Praktis}

1. Diharapkan kedepannya terdapat penelitian Food Photography di media lainnya

2. Pihak institusi memperbanyak workshop dan pelatihan yang berkaitan dengan penelitian ini

\section{Daftar Pustaka}

Scruton, R. 1981. Critical Inquiry: Photography and Representation. (vol 7). 577-603. The University of Chicago Press.

Sugiyono. 2005. Metode Penelitian Kualitatif. Bandung: Alfabeta

Vihma, S. 1995. Products as Representations: A 
Semiotic and Aesthetic Study of Design Products. Michigan: University of Arts and Design

Ambarsari, Riana. 2015. Motret Makanan itu Gampang. Jakarta: PT Elex Media Komputindo.

Carafoli, John F. 1992. Food Photography and Styling: How to Prepare, Light, and Photograph Delectable Food and Drinks. New York: Amphoto.

EmpatRana. 2011. Food Photography Made Easy. Jakarta: PT Elex Media Komputindo.

Giwanda, Griand. 2004. Panduan Praktis Fotografi Digital. Jakarta: Puspa Swara.

Rahman, Moch. Abdul. 2008. Estetika Dalam Fotografi Estetik. Jurnal Bahasa dan Seni. 36, 178-185. 